\title{
DEVELOPMENT OF $\gamma^{\prime}$ MORPHOLOGY IN P/M ROTOR DISC ALLOYS DURING HEAT TREATMENT
}

\author{
R.J. Mitchell ${ }^{1}$, M.C. Hardy ${ }^{2}$, M. Preuss ${ }^{3}$ and S. Tin ${ }^{1}$ \\ ${ }^{1}$ Rolls-Royce University Technology Partnership, Department of Materials Science and Metallurgy, \\ University of Cambridge, Pembroke Street, Cambridge, CB2 3QZ, United Kingdom \\ ${ }^{2}$ Rolls-Royce plc, PO Box 31, Derby, DE24 8BJ \\ ${ }^{3}$ Manchester Materials Science Centre and UMIST, Grosvenor Street, Manchester, M1 7HS, United Kingdom
}

Keywords: powder metallurgy, cooling rate, ageing, coarsening, LSW theory

\begin{abstract}
The microstructural evolution of $\gamma^{\prime}$ has been investigated in a series of advanced nickel-base superalloys, produced via the powder metallurgy route. The size, morphology and distribution of $\gamma^{\prime}$ within the microstructure has been found to be highly sensitive to the rate of cooling from the supersolvus solutioning temperature. Precipitate morphologies and the resulting $\gamma^{\prime}$ particle size distributions, were correlated to the various cooling rates, ranging from 6 to $600^{\circ} \mathrm{C} / \mathrm{min}$. Cooling rates below about $60^{\circ} \mathrm{C} / \mathrm{min}$ resulted in a bimodal distribution of $\gamma^{\prime}$, while rates above $60^{\circ} \mathrm{C} / \mathrm{min}$ were able to suppress the formation of tertiary $\gamma^{\prime}$ and yield a unimodal distribution of $\gamma^{\prime}$ in this set of alloys. Following the supersolvus heat treatment, the effect of ageing these various microstructures at $800^{\circ} \mathrm{C}$ was assessed. While characteristic precipitate coarsening was observed in microstructures containing a bimodal distribution of $\gamma^{\prime}$, anomalous coarsening to a critical size followed by the splitting of the $\gamma^{\prime}$ precipitates, was observed in specimens initially containing a unimodal distribution of $\gamma^{\prime}$.
\end{abstract}

\section{Introduction}

Nickel-base superalloys owe their good mechanical strength at high temperatures to coherent precipitation of the $\mathrm{L} 1_{2}$ ordered $\gamma^{\prime}$ phase in a disordered $\gamma$ matrix. $\gamma^{\prime}$ may exist as large discrete grains (typically $1-2 \mu \mathrm{m}$ ) present on the grain boundaries and occasionally within grains, as smaller secondary $\gamma^{\prime}(100-500 \mathrm{~nm})$ or as very fine tertiary $\gamma^{\prime}(<50 \mathrm{~nm})$ both present within the grains. The secondary $\gamma^{\prime}$ particle size varies inversely with the overall cooling rate. At cooling rates of higher than about $1{ }^{\circ} \mathrm{C} / \mathrm{s}$ $\left(60^{\circ} \mathrm{C} / \mathrm{min}\right)$ only one size of $\gamma^{\prime}$ is formed. Slower rates result in a bimodal distribution of $\gamma^{\prime}$. Larger precipitates form strictly on cooling and are termed secondary $\gamma^{\prime}$ while finer, tertiary $\gamma^{\prime}$ forms during the latter part of the cooling cycle. ${ }^{1}$

Development of nickel-base superalloys for turbine disc applications has focused on increasing the volume fraction of the $\gamma^{\prime}$ phase. ${ }^{2}$ For a characteristic $\gamma^{\prime}$ volume fraction, there is an optimum precipitate size and distribution of $\gamma^{\prime}$ associated with maximum strength. This is due to the ease with which dislocations can cut through/bow around the precipitates. The stress necessary for dislocations to bow around the precipitates, is inversely proportional to the inter-particle distance which increases with particle size. Such increases in the volume fraction, combined with increased levels of refractory elements, have led to difficulties in the processing of these alloys. Therefore, many modern turbine disc alloys are now produced via the powder metallurgy $(\mathrm{P} / \mathrm{M})$ route. A recently developed high strength $\mathrm{P} / \mathrm{M}$ alloy, intended for use in high-pressure (HP) turbine and compressor discs, RR1000, can be processed to produce a fine grain size. ${ }^{3-5}$ It relies on the presence of primary $\gamma^{\prime}$ to restrict grain growth. The solutioning heat treatment is followed by an ageing treatment which refines the tertiary $\gamma^{\prime}$ to a size which optimizes mechanical strength. To further optimize creep properties, coarse grained microstructures are desired to limit the extent of damage accumulation and grain boundary sliding at high temperatures. In order to accomplish this, it is necessary to solution treat the alloy above the $\gamma^{\prime}$ solvus temperature and rely on carbides and borides to pin the grain boundaries and restrict grain growth. ${ }^{6} 0$

Three experimental nickel-base alloys have been recently developed to retain a uniform medium grain size $(25-75 \mu \mathrm{m})$ (ASTM 4-8) when processed above the $\gamma^{\prime}$ solvus. $^{7}$ The as supersolvus solutioned microstructure of these alloys consists of a bimodal distribution of $\gamma^{\prime}$, the coarser forming on cooling from the supersolvus solution and the finer predominantly on ageing. Due to the supersolvus nature of the solution anneal, these alloys do not contain any primary grains of $\gamma^{\prime}$ that reside at the grain boundary.

This study has characterized the structure of these new alloys as functions of the quench rate from solution temperature and the ageing time experienced at a given temperature. Implications of the morphological changes in intragranular secondary $\gamma^{\prime}$ on hardness and strength are discussed.

\section{Experimental}

The alloys under investigation in this work were produced via the powder processing route before being consolidated via hot extrusion. Prior studies involving subscale evaluations of RR1000 have shown that the resulting microstructures and mechanical properties associated with the hot extrusion process, are very similar to conventional large-scale $\mathrm{P} / \mathrm{M}$ forgings produced via the HIP and isothermal forge route. Compositions of the experimental alloys used in this study, along with the disc alloy Udimet 720 , are summarised in Table 1 . The powder 
products were supplied by Special Metals Inc. and extruded by Wyman-Gordon Ltd. Elemental additions were vacuum induction melted before being argon gas atomized and sieved. The resulting material was placed in mild steel cans and reduced with a $5.5: 1$ area ratio reduction at $83 \mathrm{mms}^{-1}$ and $1110^{\circ} \mathrm{C}$ in an inert atmosphere, followed by an air cool. This process resulted in a starting grain size in the range 3-7 $\mu \mathrm{m}$ (ASTM 11-14).

A Netzsch DSC404C High Temperature Differential Scanning Calorimeter was used to ascertain the key solvus temperatures, principally $\gamma^{\prime}$ and carbide/boride phases. For each of the alloys a disc of $5.25 \mathrm{~mm}$ diameter and $1 \mathrm{~mm}$ thickness, with a mass of approximately $200-300 \mathrm{mg}$ was prepared. These dimensions were chosen to best match the internal dimensions of the alumina crucibles used. In addition, this specimen geometry allowed a Sapphire calibration standard of similar mass to be used. Initially, the machine was run with the calibration standard and a series of pure metals of known response, for the chosen heating rate $\left(10^{\circ} \mathrm{C} / \mathrm{min}\right)$ and gas flow rate $(50 \mathrm{ml} / \mathrm{min}$ argon). The process was then repeated with the experimental alloys, using the above parameters over the temperature range $0-1500^{\circ} \mathrm{C}$. The solvus temperatures were evaluated using Netzsch Proteus software.

Table 1 Alloy compositions (wt $\%$ )

\begin{tabular}{|c|c|c|c|c|c|}
\hline & U720 & RR1000 & UC01 & UC02 & UC03 \\
\hline $\mathrm{Ni}$ & bal & bal & bal & bal & bal \\
\hline $\mathrm{Cr}$ & 18.0 & 15.0 & 15.0 & 15.0 & 15.0 \\
\hline $\mathrm{Co}$ & 15.0 & 18.5 & 17.0 & 17.0 & 17.0 \\
\hline $\mathrm{Mo}$ & 3.0 & 5.0 & 4.0 & 4.0 & 4.5 \\
\hline $\mathrm{W}$ & 1.25 & - & - & - & - \\
\hline $\mathrm{Al}$ & 2.5 & 3.0 & 3.1 & 3.1 & 3.1 \\
\hline $\mathrm{Ti}$ & 5.0 & 3.6 & 4.4 & 4.4 & 4.4 \\
\hline $\mathrm{Ta}$ & - & 2.0 & 2.5 & 2.5 & 2.0 \\
\hline $\mathrm{Hf}$ & - & 0.5 & - & - & 0.35 \\
\hline $\mathrm{Zr}$ & - & 0.06 & 0.06 & 0.06 & 0.06 \\
\hline $\mathrm{C}$ & 0.020 & 0.027 & 0.045 & 0.045 & 0.045 \\
\hline $\mathrm{B}$ & 0.032 & 0.015 & 0.02 & 0.035 & 0.02 \\
\hline $\mathrm{V}_{\mathrm{f}} \gamma^{\prime} *$ & $47 \%$ & $47 \%$ & $52 \%$ & $52 \%$ & $52 \%$ \\
\hline
\end{tabular}

Billets $(75 \mathrm{~mm}$ in height by $65 \mathrm{~mm}$ in diameter) were subjected to supersolvus heat treatments before being cooled at 60$120^{\circ} \mathrm{C} / \mathrm{min}$. Small cubes $(5 \times 5 \times 5 \mathrm{~mm})$ of the material were also subjected to supersolvus heat treatments in Carbolite bench top furnaces, to investigate the influence of cooling rate on the resulting $\gamma^{\prime}$ morphologies. At all times the temperature was maintained to within $\pm 5^{\circ} \mathrm{C}$. Specimen temperatures and quench rates were measured using a type $\mathrm{R}$ thermocouple spot-welded to the specimen surface.

Image analysis was performed using optical microscopy, FEGSEM and TEM techniques. Measurements of $\gamma^{\prime}$ were made in two ways. Specimens were mounted and polished using standard metallographic techniques; before being electrolytically etched in $10 \% \mathrm{H}_{3} \mathrm{PO}_{4}$ in $\mathrm{H}_{2} \mathrm{O}$ at $5 \mathrm{v}$ for $2-3 \mathrm{~s}$. These samples were then analysed in the FEGSEM. For finer $\gamma^{\prime}$ particles, carbon replicas were prepared. This involved an initial etch as above, followed by the removal of over-extracted particles using a formvar in chloroform solution before sputter coating with a thin $(\sim 20 \mathrm{~nm})$ layer of carbon. This was then removed using $20 \%$
$\mathrm{HClO}_{4}$ in $\mathrm{C}_{2} \mathrm{H}_{6} \mathrm{O}$ at $5 \mathrm{v}$ for $20-30$ s. The resulting carbon replicas were placed onto copper TEM grids. $\gamma^{\prime}$ size and particle size distributions were measured using KS300 software.

The evaluation of $\gamma^{\prime}$ morphologies is open to considerable interpretation in terms of the techniques used to measure and quantify mean radii and morphologies. ${ }^{9,10}$ In this study, an equivalent diameter circle was superimposed onto the image in cases where the $\gamma^{\prime}$ precipitates were not spherical. Although this method provides the simplest analysis, care needs to be taken when assessing complex $\gamma^{\prime}$ morphologies.

X-ray diffraction was used to provide a measure of the degree of lattice misfit between the $\gamma^{\prime}$ precipitates and the $\gamma$ matrix. For all scans a Philips XPert MPD was used operating at $40 \mathrm{kV}$ and $40 \mathrm{~mA}$. The $2 \theta$ scan range was $20-120^{\circ}$, with a step size of 0.01 and a dwell time of 2 seconds. This range of $2 \theta$ enables use of the 200, 220 and 400 peaks for determining lattice parameters.

\section{Analysis of Initial Microstructure}

The microstructure of the as-extruded material is shown in Figure 1. On the micro-scale the presence of fine equiaxed grains, primary $\gamma^{\prime}$ and carbide/boride phases, can be clearly identified. At higher magnifications, with the aid of carbon replicas it is possible to see the distribution of $\gamma^{\prime}$ exhibited by these alloys following extrusion.
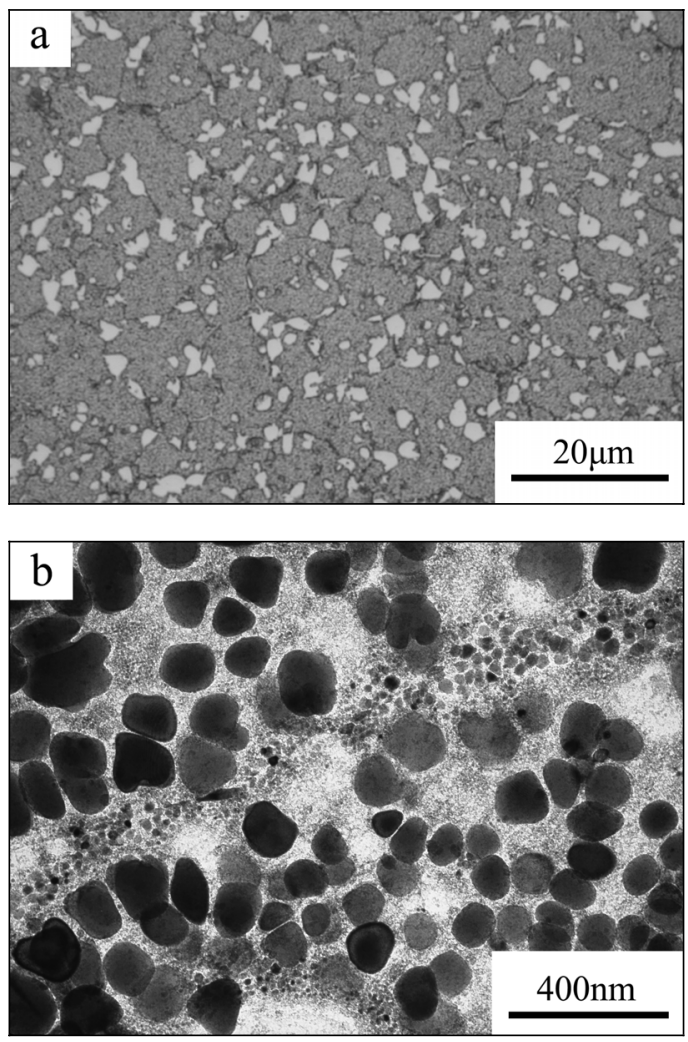

Figure 1 As-extruded microstructure reveals no preferred crystallographic texture. Average grain size is $5 \mu \mathrm{m}$ (ASTM 12). Primary $\gamma^{\prime}$ (white) can be seen in Figure 1a delineating the grain boundaries. Figure $1 \mathrm{~b}$ shows secondary and tertiary $\gamma^{\prime}$ precipitates. 
The as-extruded microstructure, Figure $1 \mathrm{~b}$, exhibits a trimodal distribution of $\gamma^{\prime}$. Primary $\gamma^{\prime}(0.5-2 \mu \mathrm{m})$ delineating the grain boundaries, with intragranular secondary $\gamma^{\prime}(100-200 \mathrm{~nm})$ and tertiary $\gamma^{\prime}(10-30 \mathrm{~nm})$.

Differential scanning calorimetry (DSC) supported by microstructural examination, was used to determine the primary phase transformations in the experimental alloys. The most important of these were the $\gamma^{\prime}$ solvus temperatures for the various alloys. The primary $\gamma^{\prime}$ solvus temperatures were determined to be in the range $1150-1200^{\circ} \mathrm{C}\left(2100-2192^{\circ} \mathrm{F}\right)$ for all three experimental alloys. In addition to the primary $\gamma^{\prime}$ solvus temperature, the carbide/boride solvus, solidus and liquidus temperatures were determined for all of the alloys under investigation. RR1000 exhibited a $\gamma^{\prime}$ solvus temperature of approximately $1145^{\circ} \mathrm{C}\left(2093^{\circ} \mathrm{F}\right)^{4}$, whereas for the experimental alloys this was approximately $27^{\circ} \mathrm{C}$ higher at $1172^{\circ} \mathrm{C}\left(2142^{\circ} \mathrm{F}\right)$. During cooling of supersolvus solutioned specimens, it was possible to ascertain the range of temperatures over which nucleation of secondary $\gamma^{\prime}$ precipitates had occurred.

\section{Effect of Quench Rate through the $\gamma^{\prime}$ Solvus Temperature on $\gamma^{\prime}$ Morphology and Mechanical Properties}

Although the physical dimensions of the billet prevented a uniform cooling rate from being attained throughout the specimen, no substantial variations in $\gamma^{\prime}$ morphology or distribution were observed for any of the alloys. Cooling the billets from the supersolvus solutioning temperature in still air at $20^{\circ} \mathrm{C}$, results in the temperature profile shown in Figure 2. The gradual cooling rate over which the majority of the material passes through the solvus temperature, was measured to be between $0.6-0.8^{\circ} \mathrm{C} / \mathrm{s}\left(36-48^{\circ} \mathrm{C} / \mathrm{min}\right)$.

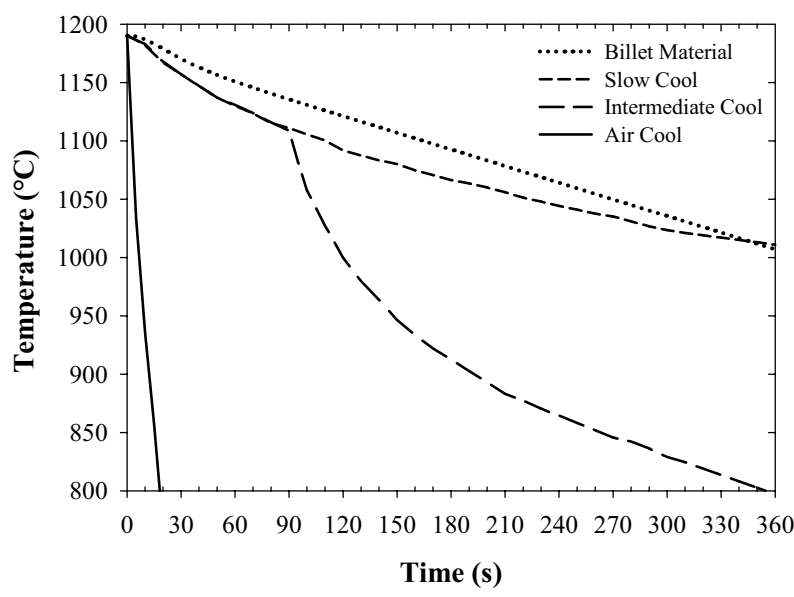

Figure 2 Cooling rates obtained for small-scale specimens and billet material. Three cooling rates were studied for the smallscale specimens; air cool $600-900^{\circ} \mathrm{C} / \mathrm{min}$, intermediate cool 60 $90^{\circ} \mathrm{C} / \mathrm{min}$ and slow cool $30^{\circ} \mathrm{C} / \mathrm{min}$.

For all of the supersolvus heat-treated alloys, the resulting microstructure consisted of a bimodal distribution of intergranular secondary and tertiary $\gamma^{\prime}$ precipitates. Gradual cooling enabled precipitation and growth of secondary $\gamma^{\prime}$ over a range of temperatures, Figure 3. The bimodal distribution of irregular secondary and fine spherical tertiary $\gamma^{\prime}$ suggest that substantial growth of the secondary $\gamma^{\prime}$ precipitates occurred prior to precipitation of the tertiary $\gamma^{\prime}$.

After an identical supersolvus heat treatment and cooling cycle, the minor changes in alloy composition did not significantly influence the distribution or morphology of the $\gamma^{\prime}$ precipitates within the microstructure. Considering that the predicted equilibrium volume fraction of $\gamma^{\prime}$ in these alloys is identical, this behaviour is not unexpected. The irregular secondary $\gamma^{\prime}$ precipitates measured approximately $(200 \mathrm{~nm})$ in diameter, while the tertiary $\gamma^{\prime}$ was substantially smaller $(\sim 15 \mathrm{~nm})$.

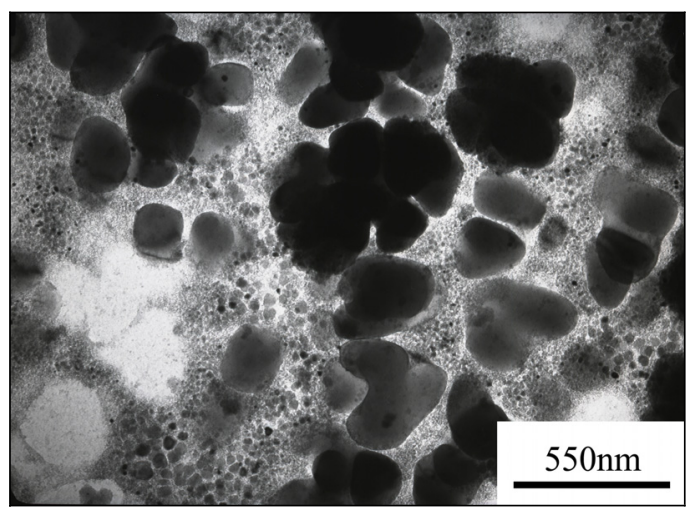

Figure $3 \gamma^{\prime}$ distribution in alloy UC02, billet material as cooled from $1190^{\circ} \mathrm{C}$ at a rate of $60-120^{\circ} \mathrm{C} / \mathrm{min}$.

The solutioning and precipitation of $\gamma^{\prime}$ in these experimental alloys was investigated using differential scanning calorimetry. At a heating rate of $10^{\circ} \mathrm{C} / \mathrm{min}$, the primary $\gamma^{\prime}$ solvus temperature for alloys $\mathrm{UC} 01, \mathrm{UC} 02$ and $\mathrm{UC} 03$ occurred at approximately $1172^{\circ} \mathrm{C}$. For microstructures consisting solely of secondary $\gamma^{\prime}$ this temperature was approximately $1160^{\circ} \mathrm{C}$.

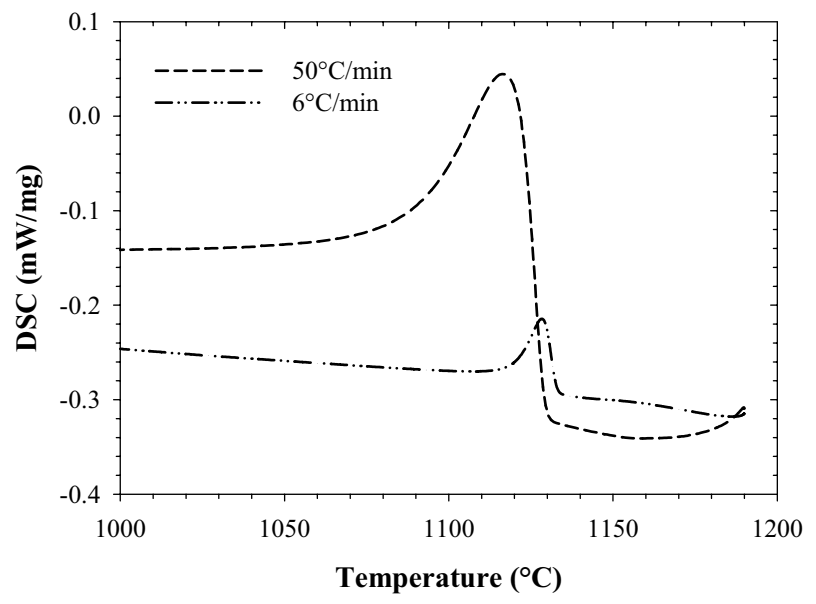

Figure 4 DSC plots of alloy UC03 for cooling rates of $50^{\circ} \mathrm{C} / \mathrm{min}$ and $6^{\circ} \mathrm{C} / \mathrm{min}$. The peak shift is approximately $12^{\circ} \mathrm{C}$.

Upon cooling, temperatures at which precipitation of $\gamma^{\prime}$ occurred in the DSC specimens was sensitive to the cooling rate. Although the DSC analysis was unable to distinguish between 
the precipitation of secondary and tertiary $\gamma^{\prime}$, by varying the cooling rate from $6^{\circ} \mathrm{C} / \mathrm{min}$ to $50^{\circ} \mathrm{C} / \mathrm{min}$ the precipitation of $\gamma^{\prime}$ can be suppressed by approximately $12^{\circ} \mathrm{C}$.

A cooling rate of $10^{\circ} \mathrm{C} / \mathrm{min}$ resulted in a significant degree of undercooling prior to the precipitation of $\gamma^{\prime}$ at $\sim 1125^{\circ} \mathrm{C}$, some $47^{\circ} \mathrm{C}$ below the measured $\gamma^{\prime}$ solvus temperature. At higher cooling rates, the formation of $\gamma^{\prime}$ was suppressed even further $\left(\sim 1116^{\circ} \mathrm{C}\right.$ at $\left.50^{\circ} \mathrm{C} / \mathrm{min}\right)$.

\section{Effect of Overall Quench Rate on Mechanical Properties and Microstructure}

Precipitation of $\gamma^{\prime}$ in these experimental alloys was also carefully characterized, utilizing small-scale specimens $(5 \times 5 \times 5 \mathrm{~cm})$ which enabled improved control of the thermal profiles during cooling, Figure 2. Although the small-scale specimens were subjected to identical supersolvus heat treatment temperatures, cooling rates were varied between 6 and $600^{\circ} \mathrm{C} / \mathrm{min}$. The resulting microstructures, Figure 5 through Figure 7, are significantly different from those present in the billet specimens.

A unimodal distribution of fine $\gamma^{\prime}$ precipitates was observed in samples cooled at $600^{\circ} \mathrm{C} / \mathrm{min}$, while a coarser bimodal distribution was seen in samples cooled at $6^{\circ} \mathrm{C} / \mathrm{min}$. The small thermal mass associated with these specimens, also enabled insitu changes in cooling rate to further investigate the precipitation kinetics of $\gamma^{\prime}$ in these experimental alloys. The resultant microstructure of $\mathrm{UC} 02$ cooled at $48^{\circ} \mathrm{C} / \mathrm{min}$ to $1125^{\circ} \mathrm{C}$ prior to being cooled at $72^{\circ} \mathrm{C} / \mathrm{min}$ to $700^{\circ} \mathrm{C}$ can be seen in Figure 6. Interestingly, a unimodal distribution of $\gamma^{\prime}$ was observed despite achieving an undercooling of $\sim 50^{\circ} \mathrm{C}$ below the solvus temperature at a rate of $10^{\circ} \mathrm{C} / \mathrm{min}$.

Solutioning above the $\gamma^{\prime}$ solvus temperature removes the grains of primary $\gamma^{\prime}$ at the grain boundaries and enhances the kinetics of grain growth. Consequently, there is an increase in the average grain size from $5 \mu \mathrm{m}$ (ASTM 12) to approximately $30 \mu \mathrm{m}$ (ASTM 7) in the experimental alloys, although this increase is more marked in isothermally forged and supersolvus solution treated RR1000. ${ }^{7}$

There is also an increase in particle size, shown in Figure 5-7, associated with a reduction in the cooling rate. At slow cooling rates $\left(30^{\circ} \mathrm{C} / \mathrm{min}\right.$ initial) tertiary $\gamma^{\prime}$ comes out of solution as fine $(<30 \mathrm{~nm})$ spherical precipitates. Coupled with this is a change in morphology of secondary $\gamma^{\prime}$ with decreasing quench rate. The secondary $\gamma^{\prime}$ is spherical at fast cooling rates, becoming cuboidal at around $1-2^{\circ} \mathrm{C} / \mathrm{s}$ and tending to 'dendritic' in the octahedral directions, cloverleaf in section at lower cooling rates.

The relationship that exists between the average $\gamma^{\prime}$ diameter and the cooling rate is shown in Figure 8. Each point reflects the average of some $100 \gamma^{\prime}$ measurements. At cooling rates faster than $\sim 100^{\circ} \mathrm{C} / \mathrm{min}$ for $\mathrm{RR} 1000$ and $\sim 10^{\circ} \mathrm{C} / \mathrm{min}$ for the experimental alloys, the formation of tertiary $\gamma^{\prime}$ is suppressed. Slower cooling rates, led to a bimodal distribution of $\gamma^{\prime}$. The larger, secondary $\gamma^{\prime}$ forms strictly on cooling. Precipitation of the fine tertiary $\gamma^{\prime}$ precipitates may occur during the latter stages of the cooling cycle or upon subsequent ageing of the alloys.
With a predominantly spherical morphology the particle size of the tertiary $\gamma^{\prime}$ is not a strong function of cooling rate. The morphology of the secondary $\gamma^{\prime}$ however, varies with cooling rate.

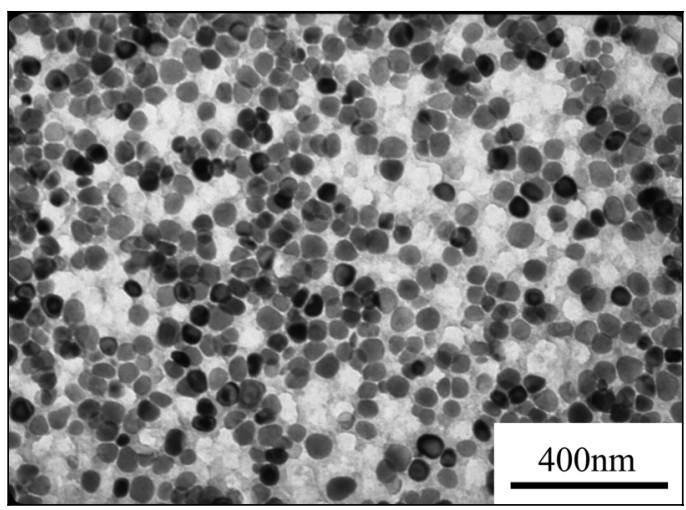

Figure 5 Specimen air cooled at $600-900^{\circ} \mathrm{C} / \mathrm{min}$. Only very fine secondary $\gamma^{\prime}(50 \mathrm{~nm})$ is present (Alloy UC02) small-scale specimen.

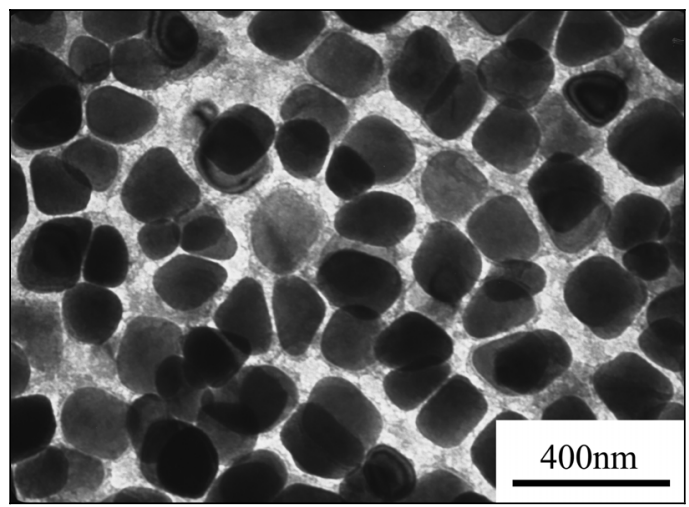

Figure 6 Specimen intermediate cooled at $60-120^{\circ} \mathrm{C} / \mathrm{min}$. Only secondary $\gamma^{\prime}(170 \mathrm{~nm})$ is present (Alloy UC02) small-scale specimen.

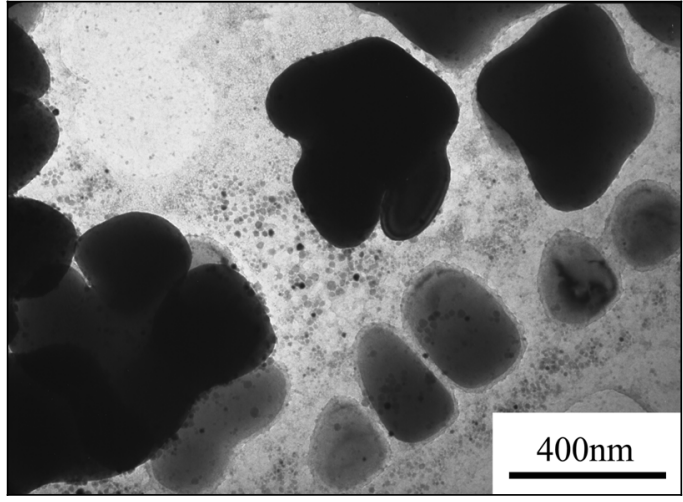

Figure 7 Specimen slow cooled at $6^{\circ} \mathrm{C} / \mathrm{min}$. Large $(370 \mathrm{~nm})$ secondary $\gamma^{\prime}$ is present with an octo-dendritic morphology, with trace amounts of tertiary $\gamma^{\prime}(15 \mathrm{~nm})$ present (Alloy UC02) smallscale specimen. 


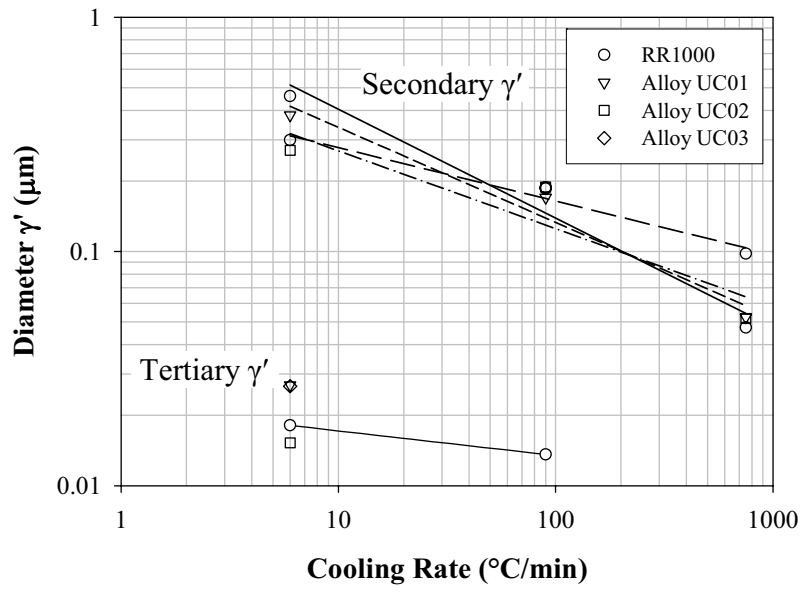

Figure 8 Effect of cooling rate on secondary and tertiary $\gamma^{\prime}$ size.

The diameter $(\mu \mathrm{m})$ of the secondary $\gamma^{\prime}$ in the as-supersolvussolutioned condition can be related to the cooling rate by an equation of the form ${ }^{1}$ :

$$
\log D_{\gamma^{\prime}}=A-B\left(\log \frac{d^{\circ} C}{d t}\right)
$$

where $\mathrm{A}$ and $\mathrm{B}$ are constants. The values obtained for the constants $\mathrm{A}$ and $\mathrm{B}$, in addition to the $\mathrm{R}^{2}$ values for the smallscale specimens, are listed in Table 2.

\section{Table 2 Regression Equation Constants}

\begin{tabular}{|c|c|c|c|}
\hline Alloy & A & B & R $^{2}$ Value \\
\hline RR1000 & 0.073 & 0.465 & 0.96 \\
\hline UC01 & -0.328 & 0.228 & 0.98 \\
\hline UC02 & -0.064 & 0.406 & 0.97 \\
\hline UC03 & -0.239 & 0.332 & 0.86 \\
\hline
\end{tabular}

The size, morphology and distribution of $\gamma^{\prime}$ have a large impact on the mechanical strength of these alloys. One way in which this can be characterised is by hardness measurements.

Figure 9 shows how the hardness of these alloys varies with the cooling rate from solution temperature. The increase in hardness with cooling rate can be rationalised on the basis of the distribution of intragranular $\gamma^{\prime}$. The cooling rates quoted are the average rates calculated over the temperature range from solutioning temperature down to $750^{\circ} \mathrm{C}$.

Alloy hardness could be directly related to the observed microstructure. The billet material contained a large amount of tertiary $\gamma^{\prime}$ in conjunction with the secondary $\gamma^{\prime}$, while a unimodal distribution of $\gamma^{\prime}$ was observed in the small-scale specimens. Consequently the billet material was measured to be harder than the intermediate cooled specimen prior to ageing.

A similar hardness response to cooling rate was observed in all of the alloys studied, following a supersolvus heat treatment. The $\gamma^{\prime}$ precipitate size and morphology were directly linked to the cooling rate. Average particle sizes were consistent irrespective of alloy composition at fast cooling rates. However at slower rates some differences in size and morphology were observed.

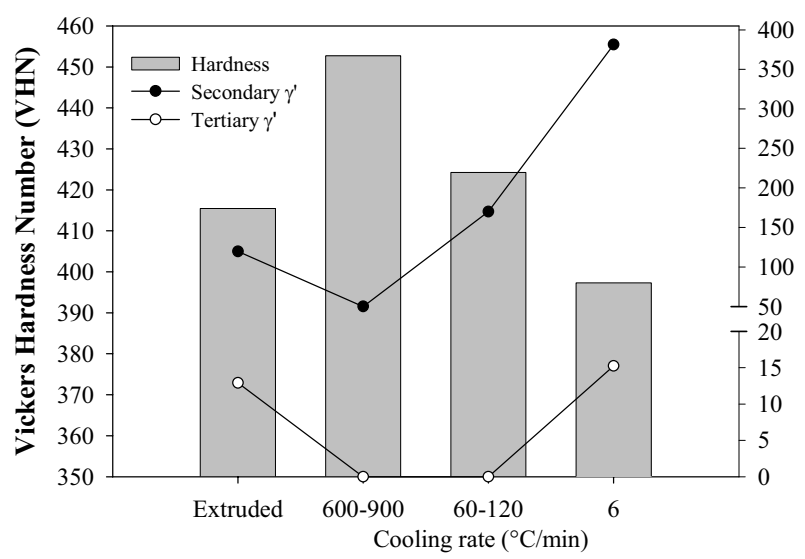

Figure 9 Variation in hardness with secondary and tertiary $\gamma^{\prime}$ size with cooling rate for alloy UC02, small-scale specimens.

\section{Microstructural Response to Ageing at $800^{\circ} \mathrm{C}$}

Ageing treatments are intended to induce precipitation of tertiary $\gamma^{\prime}$ and relieve residual stresses in forged and solution heattreated components. They may also alter $\gamma^{\prime}$ morphology. This was investigated in alloys $\mathrm{UC} 01, \mathrm{UC} 02$ and $\mathrm{UC} 03$ by subjecting them to either 4,8 , or 16 hours at $800^{\circ} \mathrm{C}$. As the initial microstructure was highly influential in determining the way in which the $\gamma^{\prime}$ develops with increasing ageing time, specimens from both the small-scale evaluations and billet were chosen for the ageing studies.

The billet material, which displayed a higher hardness following the quench when compared to the small-scale studies, exhibits peak hardness after four hours at $800^{\circ} \mathrm{C}$. With increased exposure time at $800^{\circ} \mathrm{C}$, the hardness values of all the alloys were measured to decrease as coarsening of the tertiary $\gamma^{\prime}$ occurred. This increase in both the secondary and tertiary $\gamma^{\prime}$ size is in accordance with the Lifshitz, Slyozoz and Wagner (LSW) theory. ${ }^{11-13}$

Significant differences in the hardness were observed between the billet material and the small-scale studies. These were directly attributable to the microstructure. Both the volume fraction of the $\gamma^{\prime}$ phase (both secondary and tertiary) and the size and morphology dictated the observed hardness. Alloys with different microstructure were capable of producing similar hardness values due to differences in these distributions. 

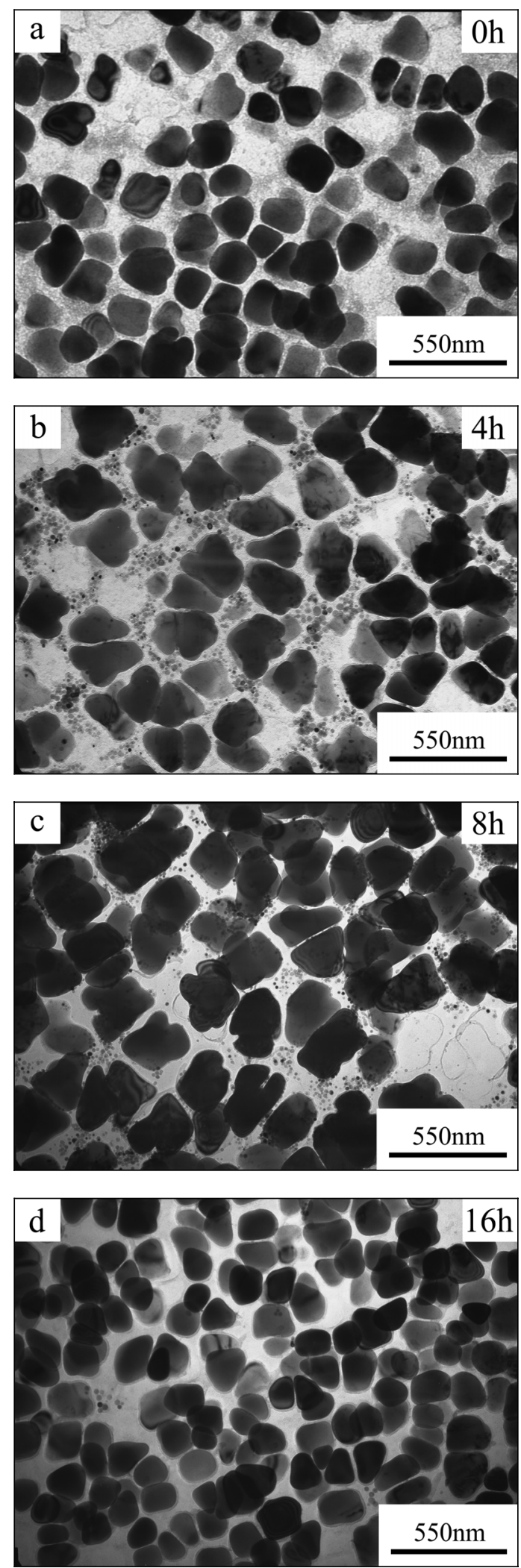

Figure 10a-d Evolution of $\gamma^{\prime}$ in Alloy UC01 during ageing at $800^{\circ} \mathrm{C}$. Small-scale specimens.
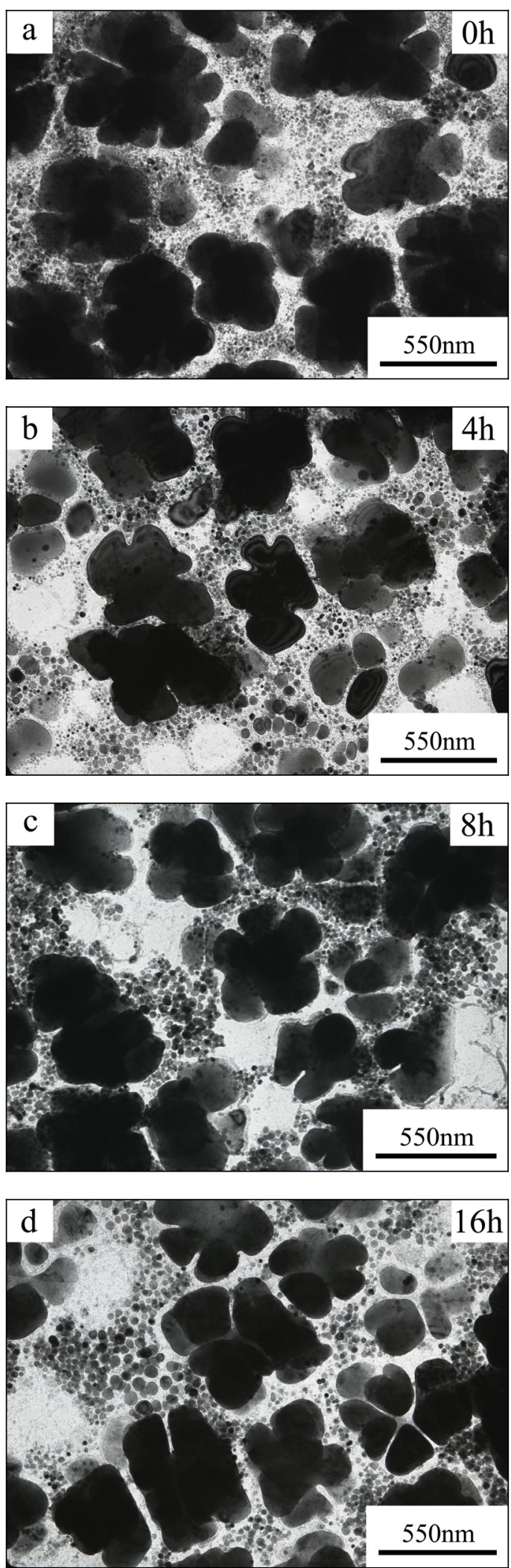

Figure 11a-d Evolution of $\gamma^{\prime}$ in Alloy UC01 during ageing at $800^{\circ} \mathrm{C}$. Billet material. 
The series of micrographs in Figure 10a-d show how the $\gamma^{\prime}$ morphology, distribution and size vary with ageing time at $800^{\circ} \mathrm{C}$ for the small-scale specimens. After four hours at $800^{\circ} \mathrm{C}$ there has been considerable coarsening of secondary $(240 \mathrm{~nm})$ and precipitation of tertiary $\gamma^{\prime}(30 \mathrm{~nm})$. Consistent with previous observations, the tertiary $\gamma^{\prime}$ remained spherical. After eight hours the secondary $\gamma^{\prime}$ is very similar in terms of size $(230 \mathrm{~nm})$ and morphology to that at four hours; however a slight reduction in the average tertiary $\gamma^{\prime}$ size $(30 \mathrm{~nm}$ to $15 \mathrm{~nm})$ was observed. After sixteen hours there is a finer secondary $\gamma^{\prime}$ distribution again $(180 \mathrm{~nm})$ and a very small amount of tertiary $\gamma^{\prime}(30 \mathrm{~nm})$.

The series of micrographs in Figure 11a-d show how the $\gamma^{\prime}$ morphology, distribution and size vary with ageing time at $800^{\circ} \mathrm{C}$ for the billet material. After four hours, coarsening of both the secondary and tertiary $\gamma^{\prime}(220 \mathrm{~nm}, 18 \mathrm{~nm})$ has occurred in the billet material. The secondary $\gamma^{\prime}$ retains an irregular morphology throughout ageing and continues to coarsen to approximately $240 \mathrm{~nm}$ after sixteen hours at $800^{\circ} \mathrm{C}$. The tertiary $\gamma^{\prime}$ remains spherical throughout and reaches $30 \mathrm{~nm}$ in diameter after sixteen hours.

As the average secondary $\gamma^{\prime}$ size increases with exposure time at $800^{\circ} \mathrm{C}$, there is a corresponding decrease in the measured hardness. It may be expected that the secondary $\gamma^{\prime}$ size would increase in accordance with Ostwald ripening at this temperature for durations of up to 24 hours, such as is seen in the billet material. However, this is clearly not the case in the small-scale specimens which contain a unimodal distribution of $\gamma^{\prime}$ prior to ageing. A critical secondary $\gamma^{\prime}$ size of $\sim 400 \mathrm{~nm}$ was observed in these samples beyond which further coarsening did not occur. Instead it appears from subsequent exposure micrographs that there is some mechanism by which there is a reduction in the secondary $\gamma^{\prime}$ size. Subsequent ageing results in coarsening and a corresponding drop in the observed hardness.

In order to understand the anomalous response of the small-scale specimens to the ageing treatment, additional intermediate hold times were studied. Although consistent with the relationship between the hardness and average secondary $\gamma^{\prime}$ size these results also showed that the secondary $\gamma^{\prime}$ coarsened irregularly to a critical size, then split into smaller cuboidal precipitates.

It appears from Figure 10a-d and the microstructures observed for different hold times, that the secondary $\gamma^{\prime}$ coarsen uniformly to a critical size prior to splitting into smaller particles, when subjected to a supersolvus solution treatment and an anneal at $800^{\circ} \mathrm{C}$. This only occurs when the solutioned material is subjected to high quench rates which suppress the formation of tertiary $\gamma^{\prime}$. Although this phenomenon occurs for all three experimental alloys and RR1000 when cooled in this manner, there is a difference in the duration of time over which the cycle takes place. In Alloy UC02 the cycle appears to be about twelve hours, however, in Alloy UC01 the cycle is much shorter, six hours and in RR1000 four hours.

Figure 12 shows a secondary $\gamma^{\prime}$ precipitate in Alloy UC03 as it begins to split. Note the 'cloverleaf' cross-section. The overall size of the precipitate is approximately $300 \mathrm{~nm}$.

One issue associated with the use of carbon replication as a technique, is analysis by TEM only allows a two-dimensional analysis of the extracted precipitates. However, analysis of the carbon replicas using FEGSEM enables these precipitates to be analysed in a pseudo three-dimensional manner. The right hand micrograph in Figure 12 shows quite clearly the secondary $\gamma^{\prime}$ precipitate splitting into eight distinct precipitates. The precipitates after the split are spherical and approximately $100 \mathrm{~nm}$ in diameter.
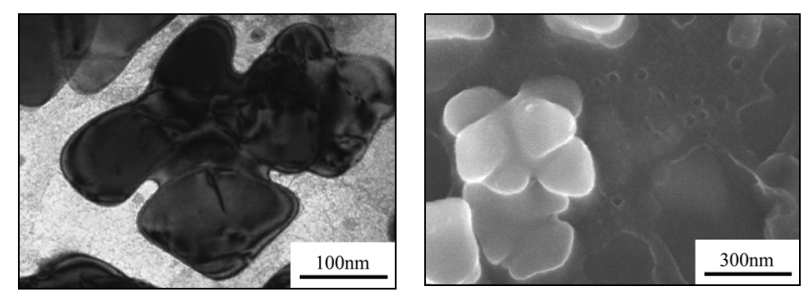

Figure 12 Alloy UC03 after ageing at $800^{\circ} \mathrm{C}$ for 8 hours. Octodendritic 'clover-leaf' secondary $\gamma^{\prime}$ morphology is clearly evident (left). Analysis using FEGSEM (right) enables secondary $\gamma^{\prime}$, seen in carbon replicas to be viewed in isometric projection.

To try and establish whether there was a relationship between the cycle amplitude (i.e. the time between successive precipitate splitting events, or peak hardness values) and the lattice misfit, $\mathrm{x}$-ray diffraction was conducted on all of the alloys following the solution treatment and quench at $1-2^{\circ} \mathrm{C} / \mathrm{s}$. Figure 13 shows a typical reflection for the (200) plane, in this instance for alloy UC02 in the as-cooled from supersolvus temperature condition. By deconvoluting the $\gamma$ and $\gamma^{\prime}$ peak it is possible to calculate the respective lattice parameters. This was done using the (400) and where possible (200) planes.

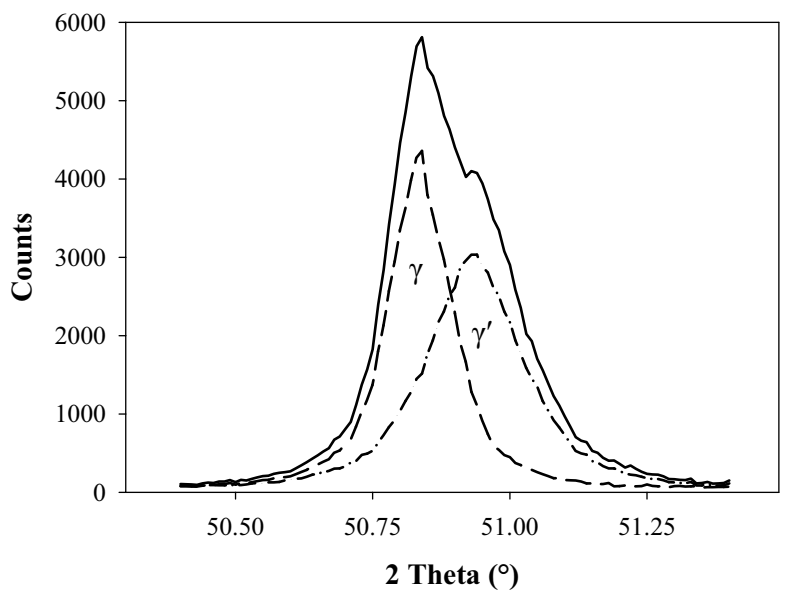

Figure 13 Deconvolution of the two (200) reflections enables lattice parameters to be calculated for $\gamma$ and $\gamma^{\prime}$. Alloy UC02 in as-cooled condition.

All of the alloys investigated in this study, displayed negative misfit values at room temperature, that is to say the lattice parameter for $\gamma$ was bigger than $\gamma^{\prime}$. At room temperature, RR1000 was found to have the highest misfit. The magnitudes of the X-ray diffraction measurements were consistent with preliminary studies of lattice misfit in these alloys using synchrotron radiation. ${ }^{14}$ 


\section{Discussion}

Processing of RR1000 and its derivatives through a powder metallurgy route, allows for greater alloying levels to be incorporated into a desirable fine grained microstructure. The potential use of a supersolvus solution also benefits high temperature creep properties. The most important part of the heat treatment of such advanced alloys, is the ability to control the microstructure during processing. The faster the cooling rate, the smaller the resultant secondary $\gamma^{\prime}$ size and the higher the hardness. The relationship between the cooling rate $(d T / d t)$ and the diameter of the secondary $\gamma^{\prime}$, can be calculated using a regression equation, Equation 1. Each of the processing steps will be discussed in more detail in the following sections.

\section{The Solution Treatment}

After solutioning at $1190^{\circ} \mathrm{C}$ for four hours grain sizes were identical in both the billet and the small-scale specimens, at around $30 \mu \mathrm{m}$ (ASTM 7). No variation in either grain size or $\gamma^{\prime}$ size/morphology was observed throughout the billet material.

Following the solution treatment the billet material for all three experimental alloys consisted of a bimodal $\gamma^{\prime}$ distribution. The larger, secondary $\gamma^{\prime}$ (approximately 200nm in diameter) and finer (approximately $15 \mathrm{~nm}$ ) tertiary $\gamma^{\prime}$ exhibited a spherical morphology. This corresponds starkly with the $\gamma^{\prime}$ distribution evident in the small-scale specimens cooled at higher rates, which consist of a closely packed distribution of secondary $\gamma^{\prime}$ (approximately 150-200nm).

The differences in $\gamma^{\prime}$ morphology/distribution that exist following the solutioning step can be rationalized in the following way: at supersolvus temperatures, all of the $\gamma^{\prime}$ returns to solution in the $\gamma$ matrix. Upon cooling, nucleation of $\gamma^{\prime}$ occurs at a rate which is highly dependent upon the cooling rate. Although the billet and small-scale specimen in Figure 3 and Figure 6 experience a similar cooling rate through the primary $\gamma^{\prime}$ solvus temperature, down to $\sim 1120^{\circ} \mathrm{C}$, the resulting microstructures are different. A two step cooling rate from the solutioning temperature was devised in an attempt to refine the $\gamma^{\prime}$ microstructure while maintaining low levels of residual stress. A rapid cooling rate to temperatures just below the $\gamma^{\prime}$ solvus followed by a controlled intermediate cooling rate to room temperature was utilized to precipitate secondary $\gamma^{\prime}$ uniformly throughout the microstructure and minimize the thermally induced stresses associated with the quenching process. Differential scanning calorimetry shows that even at a modest cooling rate of $10^{\circ} \mathrm{C} / \mathrm{min}$ the degree of undercooling before the nucleation of $\gamma^{\prime}$ is significant. At this rate it does not start to appear until $\sim 1130^{\circ} \mathrm{C}$.

There is likely to be no $\gamma^{\prime}$ present in either the small-scale specimen or the billet material on cool-down to $1120^{\circ} \mathrm{C}$. As seen in Figure 6, increasing the cooling rate in the small-scale specimen to $3.7^{\circ} \mathrm{C} / \mathrm{s}$ from $1120^{\circ} \mathrm{C}$ to $925^{\circ} \mathrm{C}$ promotes the formation of small nuclei-size precipitates with small interparticle spacing. This cooling rate is sufficiently fast to induce a microstructure in which nucleation of tertiary $\gamma^{\prime}$ can be suppressed. Continuous cooling at a slower rate, similar to that seen in the billet $\left(\sim 0.5^{\circ} \mathrm{C} / \mathrm{s}\right)$ reduces the degree of secondary $\gamma^{\prime}$ nucleation during cooling and enables coarsening of the secondary $\gamma^{\prime}$.

\section{Ageing at $800^{\circ} \mathrm{C}$}

The purpose of the ageing step is two-fold. Firstly, the $\gamma^{\prime}$ morphologies and distributions are refined to maximise the mechanical strength. Secondly, there is an element of stress relief. Residual stresses induced during machining/welding can be relieved or at least alleviated during the ageing step. During ageing, $\gamma^{\prime}$ precipitates grow by the process of Ostwald ripening and in many systems have been modelled by use of the Lifshitz, Slyozov and Wagner (LSW) theory. This theory has been heavily modified over the years by Ardell et al. and Doi et al. to account for volume fraction and particle interactions. ${ }^{11,12,15,16}$ The LSW theory predicts the mean linear dimension (r) of the precipitate particles to increase as the cube root of the time (t). It also yields an expression for the distribution of particle sizes produced by the coarsening process:

$$
r=K t^{1 / m}
$$

where $K$ is the rate constant and $m$ is a constant (usually taken as 3 which depends on the rate of diffusion). The ' $t^{1 / 3}$-law' predicts $\gamma^{\prime}$ size for given ageing times at a predetermined temperature. This can prove very useful when combined with information on mechanical properties as a function of $\gamma^{\prime}$ size.

The billet material appears to agree well with the LSW theory for diffusion controlled particle growth. For hold times of up to sixteen hours in all three experimental alloys, both secondary $\gamma^{\prime}$ and tertiary $\gamma^{\prime}$ were found to increase in diameter. This was associated with a corresponding decrease in the hardness. This agrees well with previous studies that have shown that maximum mechanical strength is associated with a large distribution of tertiary $\gamma^{\prime}$, of a certain critical diameter. ${ }^{17}$ For each alloy studied, peak hardness occurred after four hours at $800^{\circ} \mathrm{C}$.

The growth of the secondary $\gamma^{\prime}$ in the small-scale specimens, displays an unusual cyclic coarsening behaviour followed by splitting. The secondary $\gamma^{\prime}$ coarsens to a certain size before splitting into eight smaller discrete particles. These particles then have sufficient interparticle spacing to coarsen before repeating the cycle. This growth of secondary $\gamma^{\prime}$ precipitates to a point where the morphology changes has been observed before in binary alloys. ${ }^{18,19}$ However, previous studies have suggested splitting or 'inverse coarsening' of the $\gamma^{\prime}$ only occurs if the specimen has been slowly cooled from a supersolvus solution temperature, to just below the $\gamma^{\prime}$ solvus. ${ }^{15}$

Alloy designers have increased the degree of lattice misfit in an attempt to try and provide low temperature $\left(<0.6 \mathrm{~T}_{\mathrm{m}}\right)$ strength. $^{20}$ This is obtainable due to the $\gamma-\gamma^{\prime}$ interface remaining coherent despite large misfit values, only up to approximately $0.4 \%$. For alloys with near zero misfit the transition from spherical to cuboidal morphologies occurs at a much larger precipitate size. Similarly, in this work the critical precipitate size achieved before the splitting reaction is comparatively fine at $300 \mathrm{~nm}$ and is likely to be related to the high degree of lattice misfit, i.e. 
elastic strain in the matrix. ${ }^{19}$ Another factor important in the alloys studied here is the sign of the misfit. Since $\gamma^{\prime}$ is an ordered intermetallic, the thermal expansion of this phase is less than that of the matrix. This tends to increase the lattice misfit with increasing temperature in negative misfit alloys, such as those under investigation here.

Following the cool from the supersolvus solution, the secondary $\gamma^{\prime}$ is uniformly distributed within the $\gamma$ matrix in the small-scale specimens, resulting in small interparticle distances. This results in fast diffusion of atoms between precipitates. ${ }^{21}$ As the $\gamma^{\prime}$ particles grow in size, the elastic strain energy scales with the volume of the particle whereas the interfacial energy scales with the surface area. Since precipitate coarsening leads to an increase in the interparticle distance, tertiary $\gamma^{\prime}$ is able to form in these regions. As a critical particle radius is approached, the particle splits up into smaller ones to relax the elastic strain energy.

The cooling rate from the solution temperature is critical in determining the critical particle size. In the billet material, secondary $\gamma^{\prime}$, in some instances up to $400 \mathrm{~nm}$ in diameter, was observed, with only minor deviations from a spherical morphology. In the small-scale specimens, by contrast, secondary $\gamma^{\prime}$ had changed morphology and was in the process of splitting at about $250-300 \mathrm{~nm}$.

This work has emphasised the importance of the cooling rate on the resultant $\gamma^{\prime}$ morphology/distribution and its implications on mechanical properties. As the cooling rate through the $\gamma^{\prime}$ solvus can vary during both the solution heat treatment stage and during subsequent welding processes, the influence of these thermal cycles on the $\gamma^{\prime}$ morphologies need to be considered in order to optimize the properties of the finished component.

Despite the differences in composition between the alloys under investigation in this work, they all display very similar trends in response to solutioning and ageing. For polycrystalline alloys with high $\gamma^{\prime}$ volume fractions, such as these, microstructural development is highly dependent on processing parameters and to a lesser extent alloy chemistry.

The combination of high volume fraction $\gamma^{\prime}$ and a negative misfit at room temperature, when subjected to ageing at $800^{\circ} \mathrm{C}$, can result in instabilities in the microstructure of these alloys. This research has shown that for identical processing conditions there can be discrepancies in alloy response, due to the degree of lattice misfit between the $\gamma$ and $\gamma^{\prime}$ phases. Although the differences in composition (in particular of the $\gamma^{\prime}$ forming elements) are small, there can be a significant effect on the misfit values. Further work in this area using both synchrotron and neutron diffraction is planned to understand the relationship between composition and misfit.

\section{Conclusions}

- Upon cooling from $20^{\circ} \mathrm{C}$ above the solvus temperatures, no primary $\gamma^{\prime}$ was observed in any of these polycrystalline alloys. Rates above $60^{\circ} \mathrm{C} / \mathrm{min}$ resulted in a unimodal distribution of $\gamma^{\prime}$ sizes, while rates below $60^{\circ} \mathrm{C} / \mathrm{min}$ led to a bimodal distribution of precipitate sizes.

- Precipitate coarsening was observed during ageing of the supersolvus treated specimens at $800^{\circ} \mathrm{C}$. However, anomalous splitting of the $\gamma^{\prime}$ precipitates occurred in specimens with the initial unimodal distribution of precipitate sizes.

- The anomalous splitting behaviour was related to the measured lattice misfit between the precipitate and matrix. Alloys with higher levels of coherency strain were more prone to this inverse coarsening reaction.

- Optimal supersolvus heat-treated microstructures are attained when cooling rates are less than $60^{\circ} \mathrm{C} / \mathrm{min}\left(1^{\circ} \mathrm{C} / \mathrm{s}\right)$ and ageing times are four hours at $800^{\circ} \mathrm{C}$.

\section{Acknowledgements}

Financial support for this work in the form of an Industrial CASE Award between EPSRC and Rolls-Royce plc. is gratefully acknowledged. The authors would also like to thank Professor D.J. Fray for the provision of research facilities and Dr M.C. Hardy and Dr R.C. Helmink at Rolls-Royce plc. for the provision of materials.

\section{References}

1. S. T. Wlodek, M. Kelly and D. A. Alden, 'The structure of Rene 88DT', TMS Superalloys, 1996, 129-136.

2. D. P. Pope and S. S. Ezz, 'Mechanical properties of $\mathrm{Ni}_{3} \mathrm{Al}$ and nickel-base alloys with high volume fraction of gamma-prime', International Metals Reviews, 1984, 29, 136-167.

3. D. W. Hunt, 'The stability and mechanical properties of a Nickel-base turbine disc alloy', PhD Thesis, Rolls-Royce University Technology Centre, University of Cambridge, 2001.

4. A. J. Manning, 'Development of a Polycrystalline Ni-Base Superalloy for Gas Turbine Disc Application', PhD Thesis, Rolls-Royce University Technology Centre, University of Cambridge, 1999.

5. S. J. Hessell et al., 'US Patent 5,897,718', 1999.

6. R. F. Decker and J. W. Freeman, 'The mechanism of beneficial effects of boron and zirconium on creep properties of a complex heat-resistant alloy', Transactions of the Metallurgical Society of AIME, 1960, 218, 277-285.

7. R. J. Mitchell and S. Tin, 'Microstructural Effects of boron additions on powder processed Ni-base superalloys', Parsons 2003 Engineering issues in turbine machinery, power pant and renewables - 6th International Charles Parsons Turbine Conference, 2003, 721-733. 
8. B. Sundman, 'Thermo-Calc User Guide', Div. Computational Thermodynamics, 1993, KTH Stockholm.

9. D. Mukherji, S. Piegert and J. Rosler, 'Morphology of $\gamma^{\prime}$ precipitates in W- and Re- containing Ni-base superalloys', Thermec'2003 International Conference on Processing and Manufacture of Advanced Materials, 2003, 1, 815-820.

10. A. M. Wusatowska-Sarnek, M. J. Blackburn and M. Aindow, 'Techniques for microstructural characterization of powder-processed nickel-based superalloys', Materials Science and Engineering, 2003, A360, 390-395.

11. A. J. Ardell, 'An application of the theory of particle coarsening: The $\gamma^{\prime}$ precipitate in Ni-Al alloys', Acta Metallurgica, 1968, 16, 511-516.

12. A. J. Ardell, 'The effect of volume fraction on particle coarsening: Theoretical considerations', Acta Metallurgica, 1972, 20, (January), 61-71.

13. A. J. Ardell and R. B. Nicholson, 'On the modulated structure of aged Ni-Al alloys', Acta Metallurgica, 1966, 14, 1295-1309.

14. R. J. Mitchell, 'Development of a New Powder Processed Ni-Base Superalloy for Rotor Disc Application', PhD Thesis, Department of Materials Science and Metallurgy, University of Cambridge, 2004.

15. M. Doi, 'Coarsening behaviour of coherent particles in elastically constrained systems - with particular emphasis on gamma-prime precipitates in nickel-base alloys', Materials Transactions JIM, 1992, 33, (7), 637-649.

16. D. J. Chellman and A. J. Ardell, 'The coarsening of gammaprime precipitates at large volume fractions', Acta Metallurgica, 1974, 22, 577-588.

17. M. P. Jackson and R. C. Reed, 'Heat Treatment of UDIMET 720Li: The effect of microstructure on properties', Materials Science and Engineering A, 1999, A259, 85-97.

18. M. Doi, T. Miyazaki and T. Wakatsuki, 'The effects of elastic interaction energy on the $\gamma^{\prime}$ precipitate morphology of continuously cooled nickel-base alloys', Materials Science and Engineering, 1985, 74, 139-145.

19. R. A. Ricks, A. J. Porter and R. C. Ecob, 'The growth of $\gamma^{\prime}$ precipitates in nickel-base superalloys', Acta Metallurgica, 1983, 31, 43-53.

20. C. C. Law and M. J. Blackburn, 'Creep-rupture in powder metallurgical nickel-base superalloys at intermediate temperatures', Metallurgical Transactions A, 1980, 11A, 495-507.

21. C. K. L. Davies, P. Nash and R. N. Stevens, 'The effect of volume fraction of precipitate on Ostwald ripening', Acta Metallurgica, 1979, 28, 179-189. 